\title{
Fabrication of Efficient, Large Aperture Transmission Diffraction Gratings by lon-Beam Etching
}

\author{
H. T. Nguyen, S. R. Bryan, J. A. Britten, M. D. Perry
}

September 14, 2000

U.S. Department of Energy

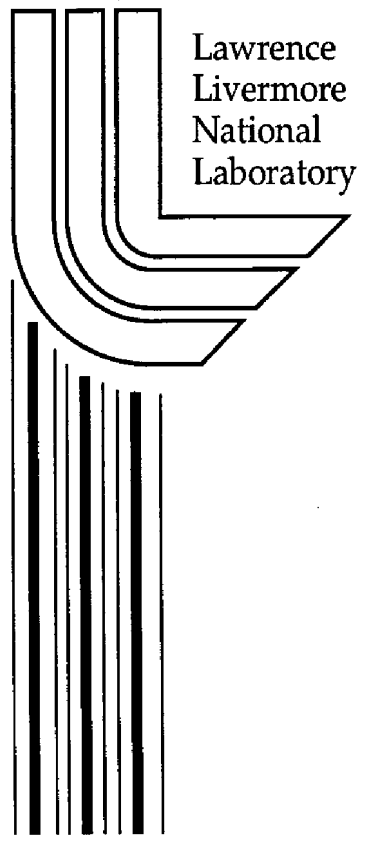




\section{DISCLAIMER}

This document was prepared as an account of work sponsored by an agency of the United States Government. Neither the United States Government nor the University of California nor any of their employees, makes any warranty, express or implied, or assumes any legal liability or responsibility for the accuracy, completeness, or usefulness of any information, apparatus, product, or process disclosed, or represents that its use would not infringe privately owned rights. Reference herein to any specific commercial product, process, or service by trade name, trademark, manufacturer, or otherwise, does not necessarily constitute or imply its endorsement, recommendation, or favoring by the United States Government or the University of California. The views and opinions of authors expressed herein do not necessarily state or reflect those of the United States Government or the University of California, and shall not be used for advertising or product endorsement purposes.

This work was performed under the auspices of the U. S. Department of Energy by the University of California, Lawrence Livermore National Laboratory under Contract No. W-7405-Eng-48.

This report has been reproduced directly from the best available copy.

Available electronically at http://www.doc.gov/bridge

Available for a processing fee to U.S. Department of Energy

And its contractors in paper from

U.S. Department of Energy

Office of Scientific and Technical Information

P.O. Box 62

Oak Ridge, TN 37831-0062

Telephone: (865) 576-8401

Facsimile: (865) 576-5728

E-mail: reports@adonis.osti.gov

Available for the sale to the public from

U.S. Department of Commerce

National Technical Information Service

5285 Port Royal Road

Springfield, VA 22161

Telephone: (800) 553-6847

Facsimile: (703) 605-6900

E-mail: orders@ntis.fedworld.gov

Online ordering: http://www.ntis.gov/ordering.htm

OR

Lawrence Livermore National Laboratory

Technical Information Department's Digital Library

http:/ / www.llnl.gov/tid/Library.html 


\title{
FABRICATION OF EFFICIENT, LARGE APERTURE TRANSMISSION DIFFRACTION GRATINGS BY ION-BEAM ETCHING
}

\author{
H.T. Nguyen, S.R. Bryan, J.A. Britten and M.D. Perry
}

\section{INTRODUCTION}

The utilization of high-power short pulse laser employing chirped-pulse amplification (CPA) for material processing and inertial confinement research is widely increasing. The performance of these high-power CPA laser system continues to be limited by the ability of the pulse compression gratings to hold up to the high-averagepower quigh c-Beak-Bgyer gf the laser in transmission and fabricated out of bulk fused silica have intrinsically the highest laser damage threshold when compared with metal or multilayer dielectric gratings that work in reflection. LLNL has developed processing capability to produce high efficiency fused silica transmission gratings at sizes useful to future Petawatt-class systems, and has demonstrated high efficiency at smaller aperture.

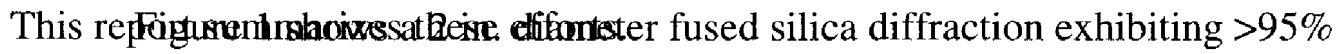
efficiency into the -1 diffraction order in transmission $\left(90^{\circ}\right.$ deflection of the incident light, at an incidence angle of $45^{\circ}$ to the grating face). The microstructure of this grating consisted of grooves ion-beam etched to a depth of 1.6 microns with a pitch of 0.75 microns, using a holographically produced photoresist mask that was subsequently strippecEqualyin significance to the fabrication of the small scale high efficiency grating was the development of the processing technology and infrastructure for production of such gratings at up to $65 \mathrm{~cm}$ diameter. LLNL is the currently the only location in the world with the ability to coat, interferometrically expose, and ion etch diffractive optics at this aperture. Below, we describe the design, fabrication, performance and, the scaleup process for a producing a high-efficiency transmission grating on a $65 \mathrm{~cm}$ fused silica substrate. 


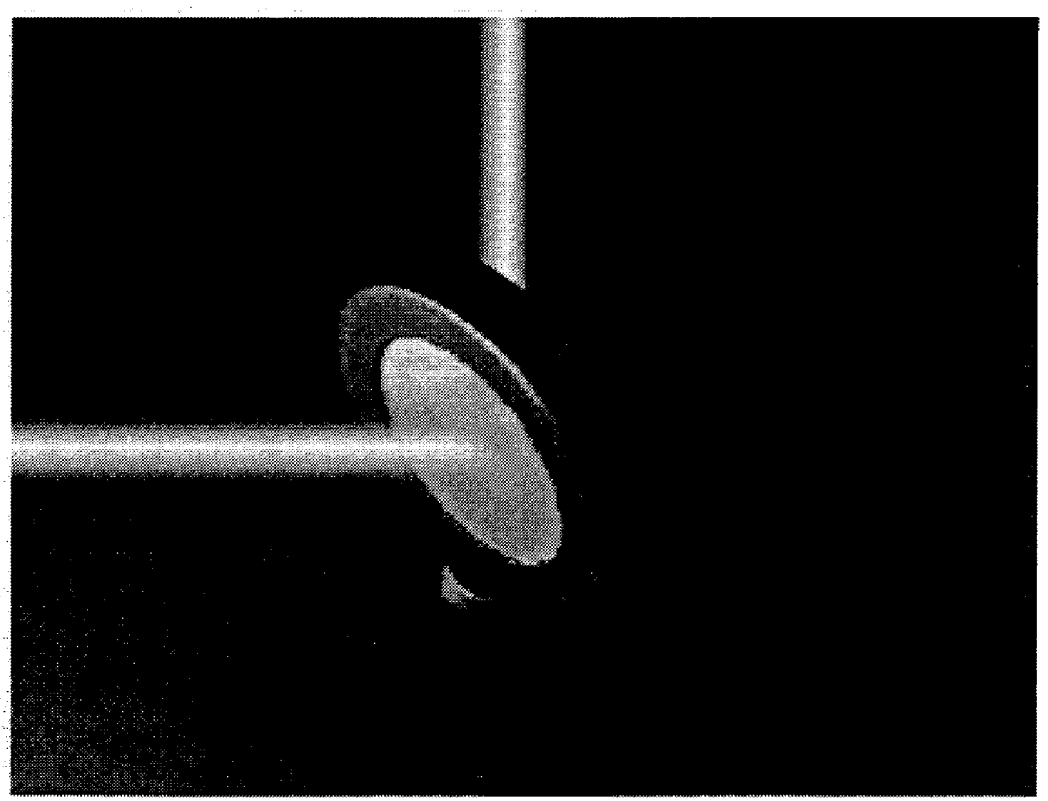

Figure 1: High efficiency (>96\%@1.06 $\mu \mathrm{m}$ ) fused transmission grating at $2 "$ size

\section{DESIGN FOR HIGH-EFFICIENCY TRANSMISSION GRATING}

The efficiency of a grating depends, for given wavelength $\lambda$, polarization and angle of incidence $\alpha$, on groove period $d$, groove depth $h$, and the shape of the grating profile. For suitable choice of these parameters the transmission efficiency can approach $100 \%$. The most efficient gratings are obtained when only two orders are allowed to propagate, namely the zero order (transmitted and reflected) and the -1 order (diffracted and Littrow). By making the period small for given wavelength we can exclude all other orders except 0 and -1 . This possibility follows from the basic grating equation relating angle of incidence $\alpha$ to angle of diffraction $\beta_{\mathrm{m}}$ for order $m$,

$$
\sin \beta_{\mathrm{m}}=\sin \alpha+(m \lambda / d) \text {. }
$$

Our goal for permitting only two orders can be assured by fixing the grating period to be smaller than the wavelength. For light of wavelength $1050 \mathrm{~nm}$ this implies a groove period of $1050 \mathrm{~nm}$ or less. 
The geometry of diffraction is entirely set by the grating equation, and is independent of groove depth or profile. With period $=750 \mathrm{~nm}$ the Littrow angle for 1.05 micron light (the angle at which reflective diffraction into order -1 coincides with incident radiation) is $45^{\circ}$. With this incident angle the transmitted light into order -1 emerges into air at an angle of $45^{\circ}$. Thus there will be a $90^{\circ}$ angle between the two

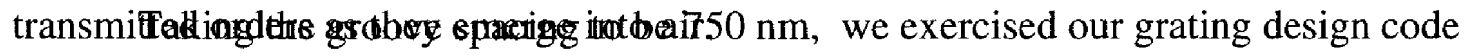
and found that there was a range of parameters at which the theoretical efficiency was $98 \%$ or better. The optimal design for $750 \mathrm{~nm}$ at this wavelength was a depth of around $1550 \mathrm{~nm}$, and with duty cycle of 0.4 (i.e. the grooves are $\sim 300 \mathrm{~nm}$ wide), to be used with TE polarized light. Figure 1 illustrates the profile and efficiency for this design. This design has a theoretical efficiency of $98 \%$ into $m=-1$ order.

Figure 2. Right: Theoretical transmission efficiency, $\lambda=1053 \mathrm{~nm}$, order -1 and TE polarization, as a
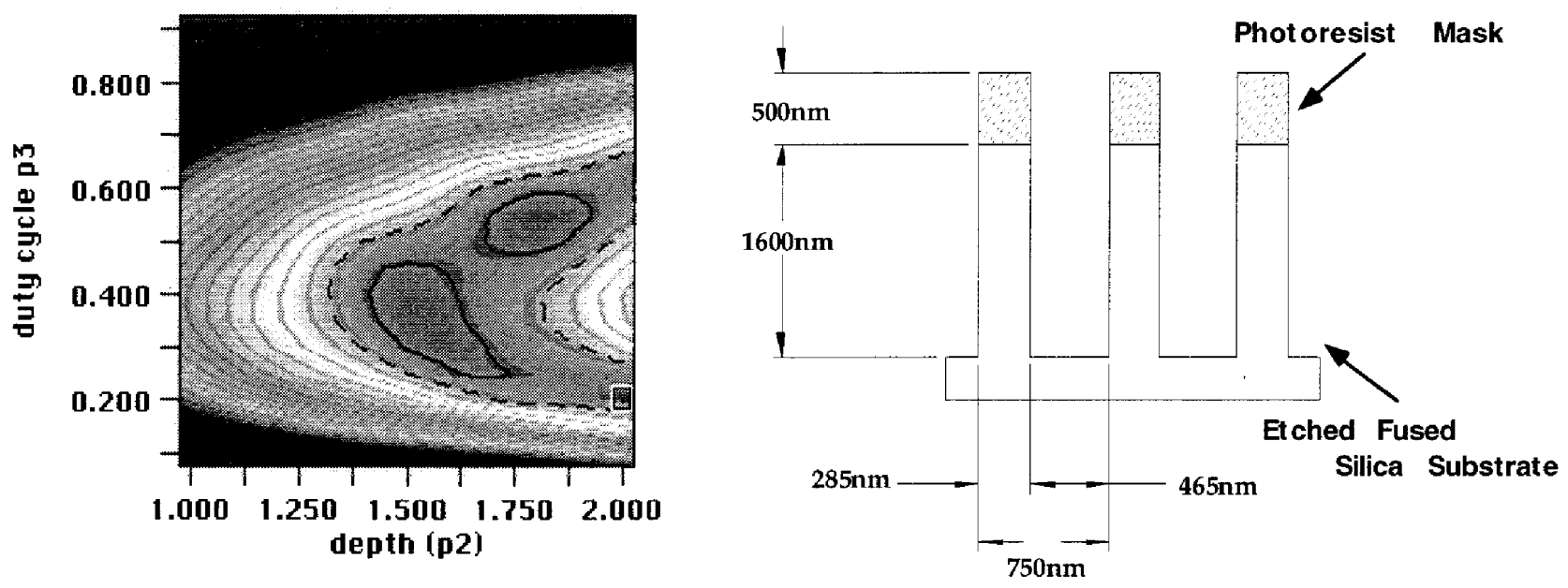

function of groove depth (nm) and duty cycle for a rectangular-profile grating etched into silica (left frame). Incident angle is Littrow angle, groove spacing is $\mathrm{d}=750 \mathrm{~nm}$. The peak efficiency $(98.4 \%)$ occurs for depth of $1550 \mathrm{~nm}$ and duty cycle 0.38 .

\section{GRATING FABRICATION}


In this section we briefly describe the procedures we followed in preparing the photoresist masks. Fused silica substrates were selected because they exhibit a high damage threshold, no measurable birefringence, and because they are suitable candidates for reactive ion beam etching. These substrates are polished to an overall surface quality of $\lambda / 10$ for 633 nfm light and followed by a mild hydrofluoric acid etch, a distilled-water rinse, and a dry-nitrogen blow dry. They were subsequently baked for several hours at $120^{\circ} \mathrm{C}$, cooled down to $80^{\circ} \mathrm{C}$, and then vapor primed with hexamethyldisilazane (HMDS, a priming agent to facilitate

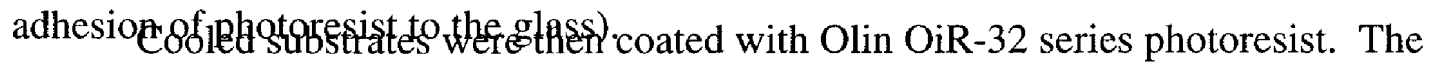
coating process depended on the substrate size. Two-inch witness parts were spin-coated. Larger parts were meniscus coated. After coating, parts were baked at $80 \mathrm{C}$ for a time that again depended on the substrate size. Coating application rates and resist concentrations were adjusted to obtain a final resist film thickness of approximately $0.60 \mu \mathrm{m}$. An absorptive strip-paint was applied to the back of the substrate to prevent spurious reflections during the exposure.

\section{EXPOSURE PROCESS}

A laser interference holographic technique is used to record the desired grating pattern in the photoresist. The holographic exposures were made by illuminating the photoresist-coated substrates with two plane waves in a fringe-stabilized interferometer that uses a $1.5 \mathrm{~W}$, single-frequency $\mathrm{Kr}$-ion laser operating at $413 \mathrm{~nm}$. A more detailed description of the set-up is describe elsewhere ${ }^{k}$. Because of the relative insensitivity of this particular high-contrast photoresist at $413 \mathrm{~nm}, 100 \mathrm{~mJ} / \mathrm{cm}^{2}$ exposures were required. The interferometer table was set up to produce $675 \mathrm{~nm}$ period gratings for other projects. Therefore, a rotation of the parts of $\delta=25.8^{\circ}$ with respect to the exposure plane centerline was required to produce a period of $750 \mathrm{~nm}$, according to the grating equation at exposure conditions: 
$\mathrm{D}=\lambda /(2 \sin \alpha \cos \delta)$

where $\alpha=17.8^{\circ}$ for normal exposure for $\mathrm{d}=675 \mathrm{~nm}$.

After exposure, the photoresist was immersion developed in AZ-300MIF developer at room temperature. The development was stopped after $30 \mathrm{sec}$ with a deionized water wash.

Figure 3 shows examples of SEM profiles produced on witness parts. These measurements were made on cleaved samples that had been coated with a thin layer $(100 \AA)$ of palladium.

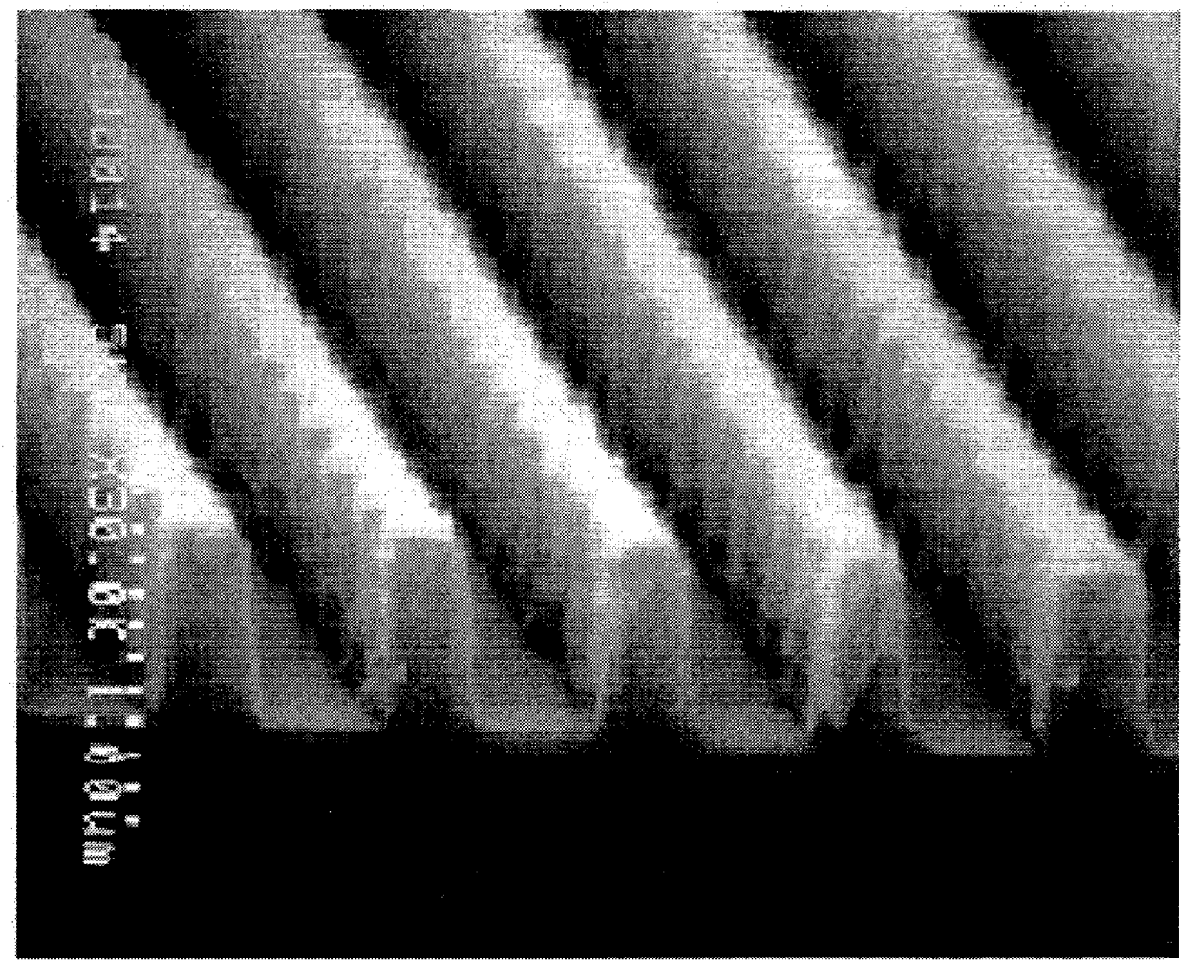

Figure 3. Grating profile patterned in photoresist, period $=750 \mathrm{~nm}$, height $=600 \mathrm{~nm}$, and duty cycle $=0.40$.

\section{REACTIVE ION BEAM ETCHING}

Transfer of the photoresist grating pattern to the fused silica substrate was accomplished by $\mathrm{CHF}_{3}$ reactive ion beam etching (RIBE). With a RIBE, we have the 
capability to scale these gratings up to $80 \mathrm{~cm}$ in diameter, which is necessary for use in the laser system. Specific procedures depend on the actual machine used. However, we found the primary variables were reactive gas flux, ion energy, and ion flux.

Following etching, excess resist was removed by stripping with sodium hydroxide solution. Figure 4 shows SEM profiles on a witness part thusly produced.

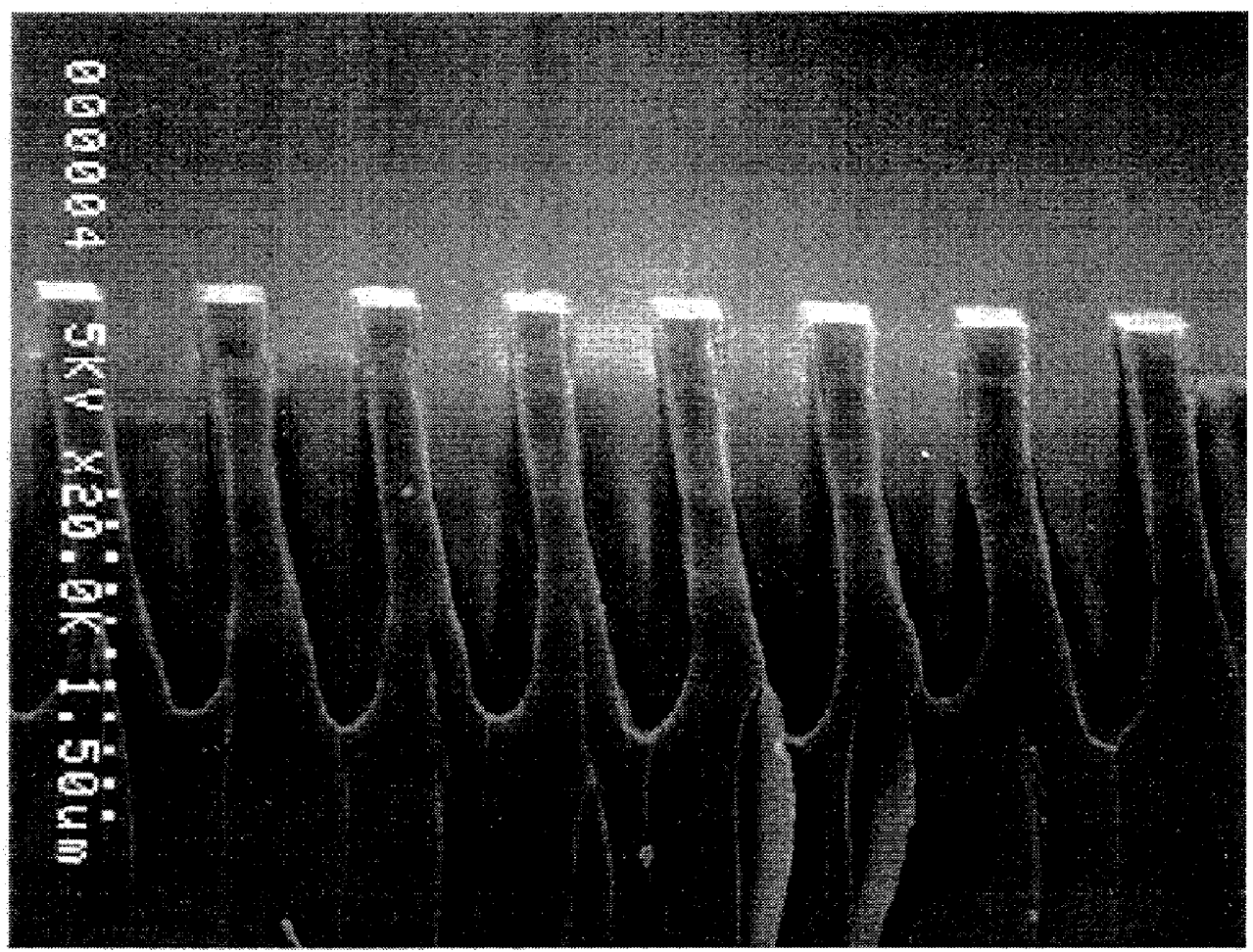

Figure 4. Grating etched into bulk fused silica: period $=750 \mathrm{~nm}$, height $=1.75 \mu \mathrm{m}$, duty cycle $=0.35$.

We have fabricated a 2" diameter grating that exhibits diffraction efficiency distributions summarized in Figure 5. $\mathrm{Nr}$

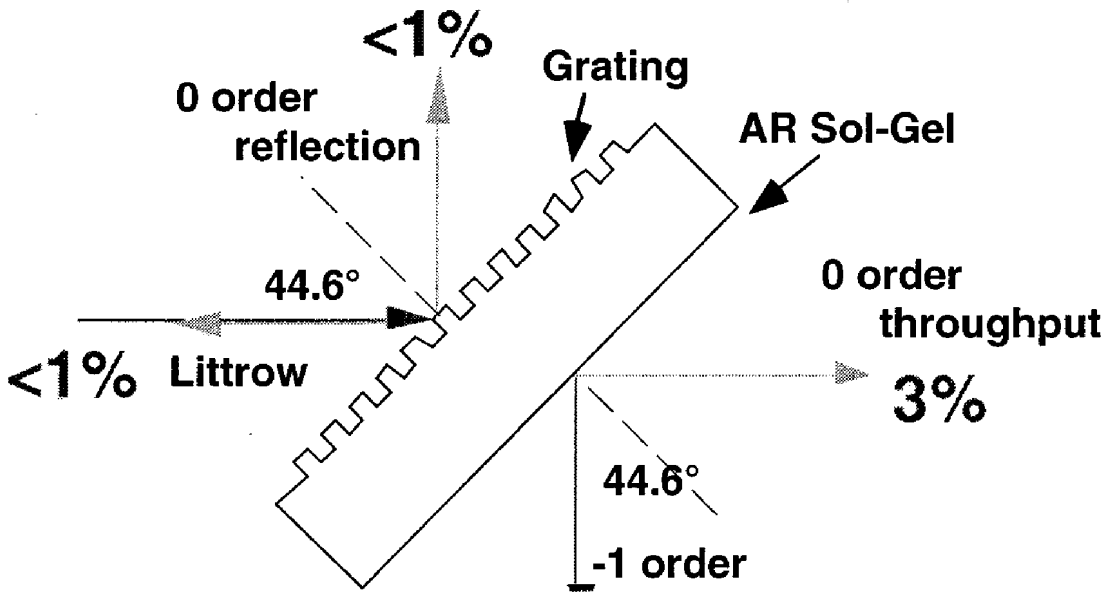


o other ambient reflections or diffractions could be seen.

Figure 5. Measured diffraction efficiency at 1.06 micron, TE polarization, for 2 in. diameter grating in fused silica.

Measured diffraction efficiencies are in good agreement with our theoretical computations. Figure 6 is a plot of the measured and theoretical diffracted efficiencies

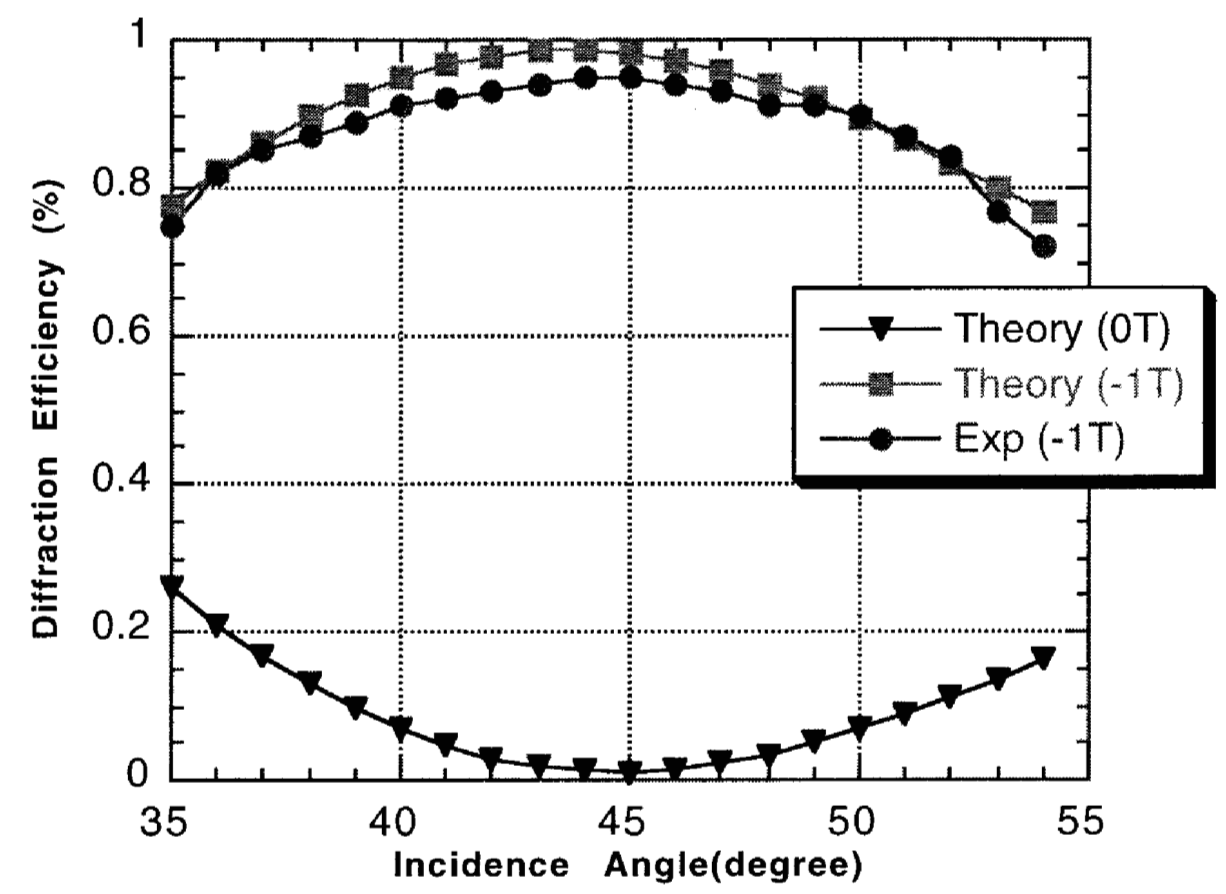

for the groove shape measured for TE polarization.

Figure 6. Maximum diffraction efficiency as a function of angle for $m=-1$ order. Grating period $=750$ $\mathrm{nm}$, height $=1750 \mathrm{~nm}$, and duty cycle $=0.35$.

\section{SCALE UP TO METER SIZE SUBSTRATES}

Equipment and technology to wet-process transmission gratings up to $80 \mathrm{~cm}$ aperture is already in place as a result of the Petawatt project. Significant development of ion-beam etching capabilities was needed to produce a submicron-pitch transmission grating at this size. Our Oxford etcher system originally consisted of a $40 \mathrm{~cm}$ ion gun 
with collimating grids configured to optimize the ion current density over a $30 \mathrm{~cm}$ aperture. To process larger parts, we inverted the collimating grids to create a diverging ion beam. Next, we mounted the part at the center of the rotating target platen, and designed a wedged mask in front of the part to compensate for the radial variation in ion flux and the radial change in effective etching time of the rotating part. The basic geometry of this setup is shown in Figure 7.

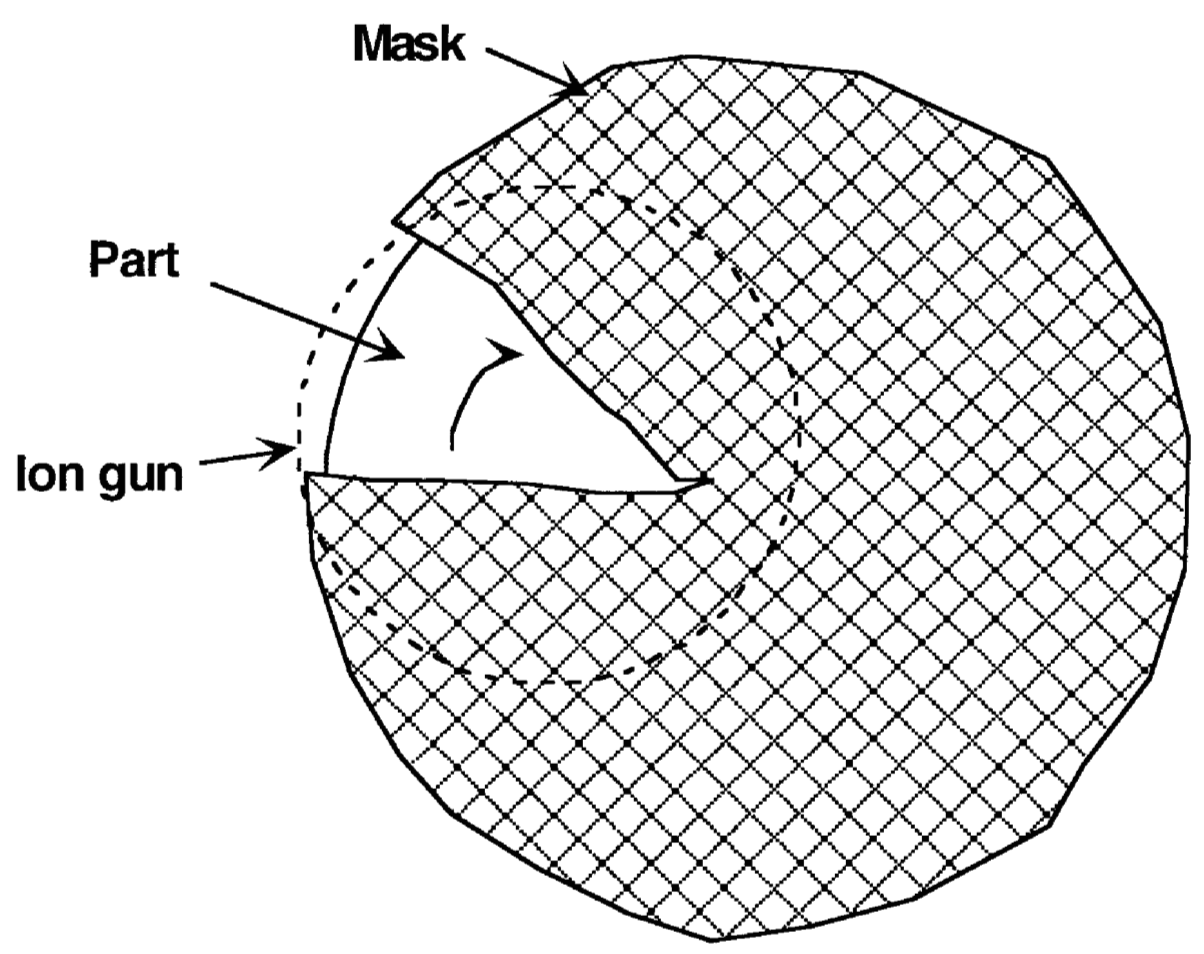

Figure 7. Geometry of mask, substrate and ion gun in ion-beam etcher

Laborious trial and error etch runs using witness parts mounted at different radial positions along the substrate mounting fixture, followed by SEM analysis of the etched parts, was required to tailor the detailed shape of the wedge edges to produce radial etch rates that were nominally uniform to within $+/-5 \%$. This was accomplished except for the center 5-7 $\mathrm{cm}$ diameter region, which suffered from low ion flux. It was decided to etch a $65 \mathrm{~cm}$ grating substrate that was exposed, developed and characterized by atomic 
force microscopy. Due to the expense of these substrates and time considerations, we only had one chance at this size. The substrate was etched in September of ' 99 , stripped at one small location near the edge, and measured with 1.06 micron light at Littrow angle. This measured diffraction efficiency was lower than expected. Atomic force microscopy at this location suggested groove depths that were too low. It was decided to place the part back in the etcher to deepen the grooves. The part was then harvested, stripped of the resist mask, and subjected to full-aperture photometry at use wavelength and polarization. A photograph of the part is shown in Figure 8. It is quite efficient and visually arresting in visible light.

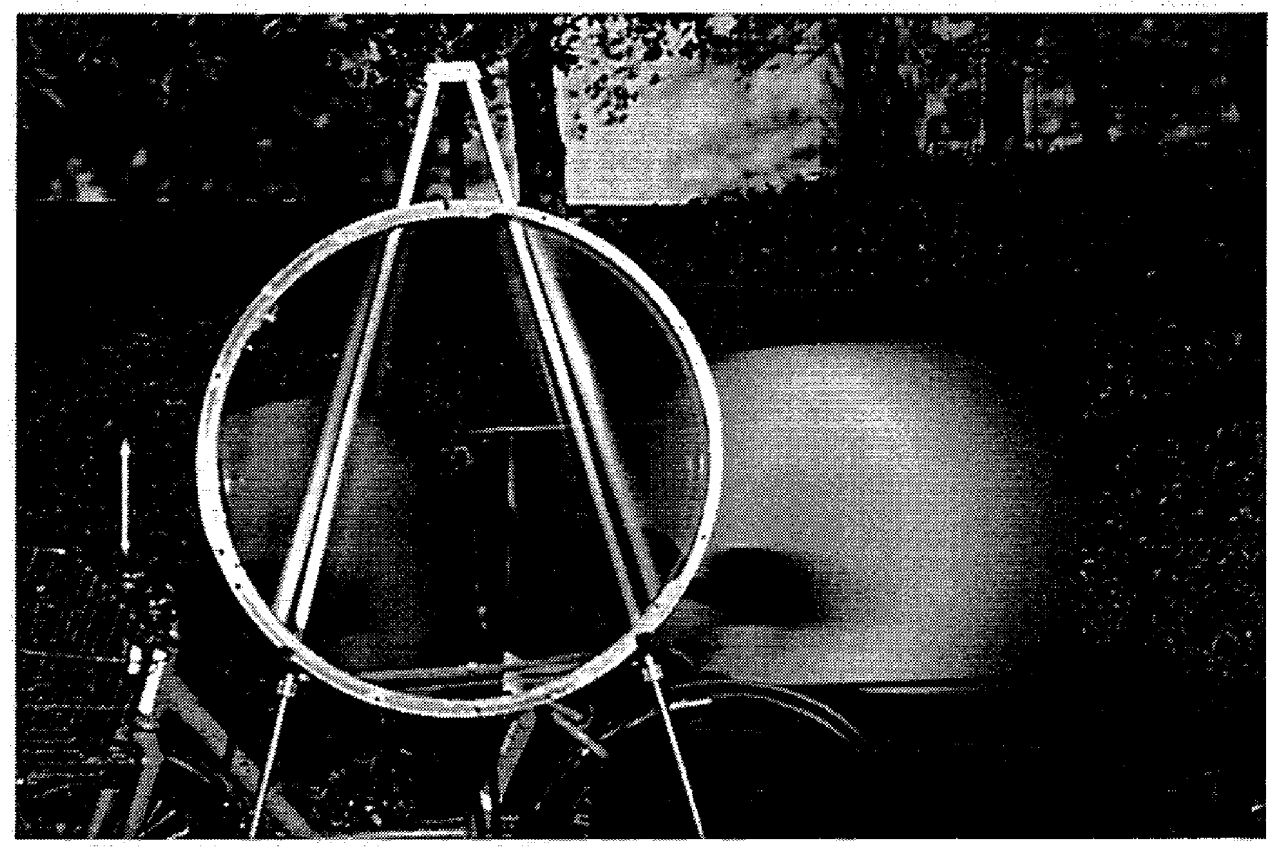

Figure 8. Initial $65 \mathrm{~cm}$ diameter fused silica transmission grating

There are two major problems with this grating at use conditions; 1) it exhibits a low overall diffraction efficiency in $m=-1$ order and 2) the efficiency varies radially. Lineouts of efficiency in -1 and 0 orders are shown in Figure 9. The grating substrate has a hole drilled in the center. Due to this and to the known nonuniformity in ion flux in the etcher near the center, the data in this region is deleted from Figure 9. The efficiency did not change appreciably between the first and second etches. 


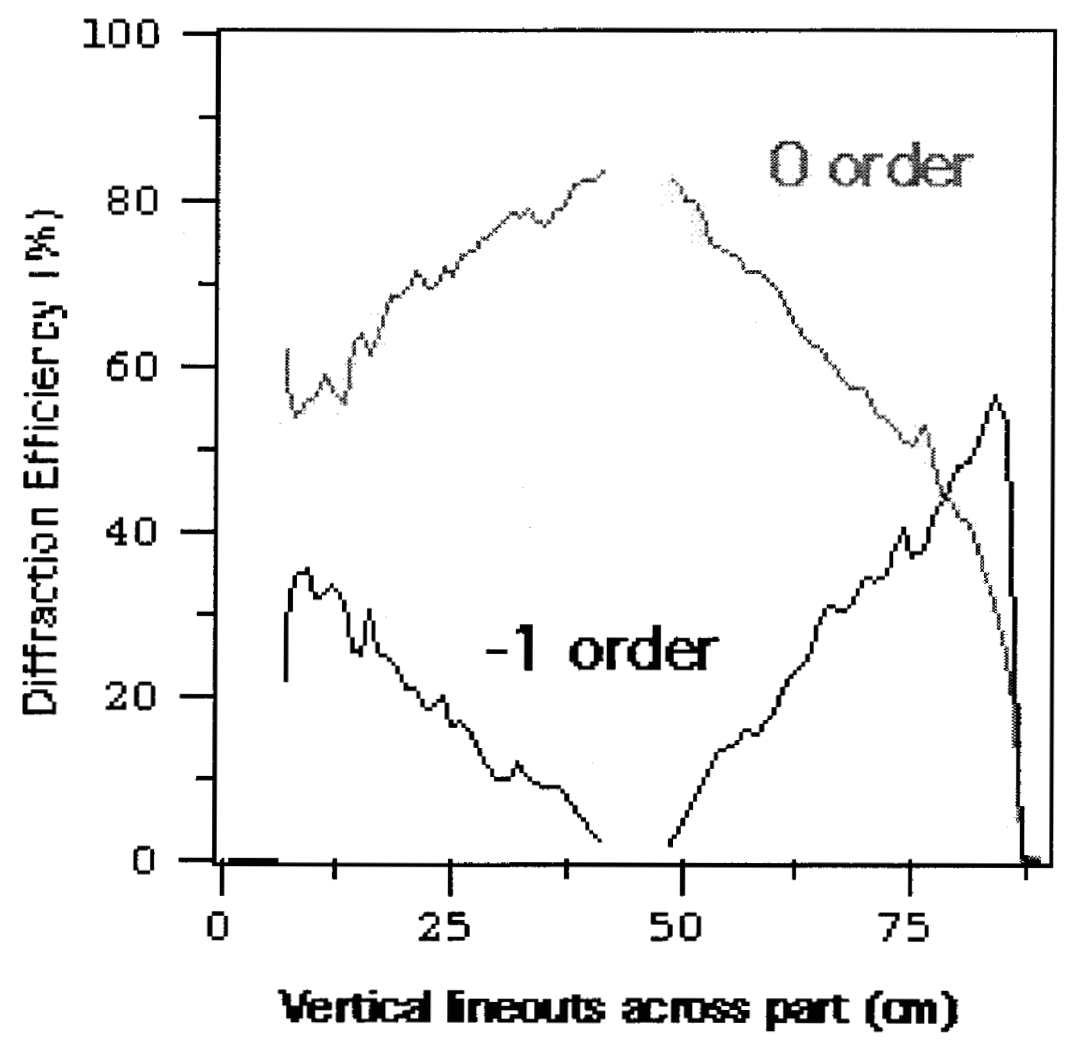

Figure 9. Diffraction efficiency as a function of angle for $\mathrm{m}=-1$ and $\mathrm{m}=0$ order. Grating period $=750$ $\mathrm{nm}$, height $=1750 \mathrm{~nm}$, duty cycle $=0.35$ and, diameter $65 \mathrm{~cm}$.

We believe that the discrepancy of diffraction efficiency between the 2" diameter and the $65 \mathrm{~cm}$ diameter part is due to a malfunction oxygen flow controller in the ion etcher. This malfunction caused the an over flow of oxygen, which in turn completely etched away the photoresist mask used to protect and produce the fused silica grating structure. Therefore, it was not possible to attain the desired groove depth. This explains the lack of change in the grating performance after the second etch - the second etch basically drove the pre-existing profiles into the bulk without changing the depth. The cause of the radial variation in efficiency is more speculative. It could be a radial variation in duty cycle due to exposure nonuniformities. We are only able to measure the microstructure about $10 \mathrm{~cm}$ in from the edge of the part with the atomic force microscope. The part is too big to measure near the center. Other optical diagnostics are 
not sensitive enough to tell the duty cycle of the part in resist. If time and funding permits, another attempt can be made and a stand-alone AFM head can be used to image the profiles over larger areas on the part before ion etching.

\section{CONCLUSION}

We have designed and produced a high-efficiency transmission gratings fabricated in bulk fused silica for in high-power laser systems. These gratings were designed to diffractively compress $1050 \mathrm{~nm}-1070 \mathrm{~nm}$ light. We have obtained diffracted efficiencies greater than $95 \%$ for $m=-1$ order in a near-Littrow configuration for a 2" diameter substrate. In addition, we have produce a $65 \mathrm{~cm}$ diameter bulk fused silica transmission grating that exhibits diffracted efficiency in places greater than $82 \%$ for $m=$ Whifeley.e have made significant advances towards developing the ability to produce master gratings at this size, there are still several outstanding technology issues to be addressed. 